\title{
Pandemia de Covid-19: agenda de pesquisas em contextos de incertezas e contribuiçôes das ciências sociais
}

\section{| ${ }^{1}$ Marcia Grisotti |}

\author{
${ }^{1}$ Núcleo de Ecologia Humana e Sociologia da Saúde, Departamento de Sociologia e Ciência Política, Universidade Federal de Santa Catarina. \\ Florianópolis-SC, Brasil (marcia.grisotti@ufsc.br). ORCID: 0000-0003-0389-7100 \\ Recebido em: 19/04/2020 \\ Aprovado em: 24/04/2020 \\ Revisado em: 28/04/2020
}

DOI: http://dx.doi.org/10.1590/S0103-73312020300202

Pandemias ocorreram ao longo da história e ocasionaram profundas rupturas no sistema social. O que aprendemos com a história social das epidemias? Apesar do avanço científico e tecnológico dos últimos séculos, dispomos apenas, em termos práticos e no curto prazo, de dispositivos de biossegurança medievais, ou seja, de práticas existentes bem anteriores à descriçáo da teoria dos germes: a quarentena, a instalação de cordóes sanitários nas fronteiras dos Estados-naçóes e o isolamento social.

No início do ano de 2020, fomos confrontados diante de uma doença infecciosa emergente, para a qual não há tratamento, nem vacina, nem imunidade preexistente. Além disso, os processos de tomada de decisóes estáo baseados em protocolos que mudam conforme os contornos dinâmicos apresentados pela origem e distribuiçáo do vírus (e da infecção) em diferentes indivíduos e grupos; em conhecimento científico ainda incipiente (apesar do intenso esforço de equipes internacionais de pesquisas), especialmente sobre o papel dos portadores assintomáticos, sobre a relação entre infecção e imunidade e sobre a especificidade e sensibilidade dos testes diagnósticos. Nesse contexto de incertezas, somos forçados a alterar a rotina e os laços sociais, através do distanciamento social que permite a redução da velocidade de dispersão do vírus e, consequentemente, do número de pessoas que, simultaneamente, precisariam da estrutura hospitalar de alta complexidade para o tratamento dos sintomas graves. 
O isolamento (ou a resistência a este) é uma prática com múltiplas variantes; dependendo de quem e onde é isolado e sua implantação enquanto estratégia de saúde pública, coloca em evidência uma série de desafios e consequências sociais. $\mathrm{O}$ peso das desigualdades sociais e a existência de muitos grupos vulneráveis se tornam evidentes no momento da adoção de medidas de contingência para o controle de epidemias. Afinal, como está proposto o distanciamento social para grupos vulneráveis economicamente? Como viabilizar a higiene em locais carentes de infraestrutura básica de saneamento? Em geral, a resposta é: nesse caso, não há o que fazer no momento! Em outro lado desse cenário, os profissionais de saúde são colocados na linha de frente diante de uma situação de risco e incertezas, em que a transmissão por contato depende das características do vírus e das pessoas infectadas, da qual eles precisam dar conta, e também das condiçóes de trabalho.

No contexto de um mundo globalizado (marcado pela circulação rápida de pessoas, animais, plantas e mercadorias, os quais intensificam a disseminação de micro-organismos), o distanciamento social, preconizado como medida oficial dos governos para conter a curva epidêmica do Covid-19, traz, como consequência, profundos impactos sociais, culturais e econômicos, assim como estratégias de resiliência frente às incertezas. São inúmeras as dimensóes de análises (estruturais e subjetivas) advindas dessa experiência, assim como a prospecção de novas agendas de pesquisas: a capacidade de resposta do sistema de saúde, a capacidade de registro e notificação de epidemias, a produção de conhecimento sobre o vírus, a doença e os doentes, os impactos econômicos, o papel da Organização Mundial da Saúde (OMS) frente aos novos atores em saúde global, a fragilidade do pacto federativo no Brasil (relaçôes entre os governos estaduais, municipais e federal) na gestão da pandemia, as diferentes reaçôes dos líderes políticos, a tensão entre liberdade individual e as medidas de saúde pública, a definição de atividades essenciais durante o distanciamento social, as novas configuraçóes do trabalho e do domicílio em momento de confinamento, a noção de corpo saudável e de imunidade, as regras de higiene e uso de máscaras protetoras, as narrativas em relação à vivência em isolamento social, a percepção pública da ciência, as notícias falsas, entre outras.

Das várias dimensôes analíticas sobre a pandemia, vou me deter aqui em alguns aspectos que podem alimentar o debate sobre por que, apesar de inúmeras pesquisas publicadas sobre doenças infecciosas emergentes e dos alertas sobre possíveis 
epidemias em escala global, nos surpreendemos (especialmente os pesquisadores) com o que estamos vivenciando.

Um aspecto do debate é interno à ciência e diz respeito a uma certa tensão entre algumas abordagens teóricas. Refiro-me especificamente às controvérsias em torno da teoria da transição epidemiológica e o impacto que o conceito de doenças infecciosas emergentes possui na forma de pensar relacionalmente (ELIAS, 1999; BOURDIEU, 1998) as interaçôes humanos-animais-ambiente e, consequentemente, na defesa da perspectiva interdisciplinar da produção de conhecimento.

As expectativas de controle e erradicação de doenças infecciosas e parasitárias - com o advento da teoria da origem microbiana das doenças infecciosas, seguidas pela produção de soros e vacinas no fim do século XX, bem como pela descoberta de sulfas e antibióticos no século XX - não se confirmaram. A emergência da Aids, de um grande número de doenças zoonóticas no final do século XX e da descoberta da origem infecciosa de muitas doenças crônicas fragilizaram o conceito de transição epidemiológica, no qual supunha-se (ou especulava-se) que as doenças infecciosas e parasitárias dariam lugar às condiçôes crônicas e degenerativas como as principais causas de mortalidade e morbidade humana (GRISOTTI; AVILAPIRES, 2010; 2016).

Além disso, o tempo da ciência é elástico e limitado em comparação com o tempo de dispersão dos micro-organismos. Os micro-organismos são versáteis e possuem um amplo alcance de adaptaçôes às condiçôes ambientais adversas. Avanços no entendimento sobre seus processos biológicos, na produção de novas geraçôes de medicamentos e vacinas e no melhoramento de barreiras sanitárias para impedir sua dispersão têm-se mostrado mais lentos do que a capacidade de mutação, recombinação e dispersão demonstrada pelos micro-organismos (OCHMAN; LAWRENCE; GROISMAN, 2000). No caso da Covid-19, a distância entre o tempo da ciência e o tempo da infecção coloca outros impasses, como por exemplo, a tese da herd immunity, defendida inicialmente pelos governos da Holanda e da Inglaterra como uma estratégia alternativa ao isolamento total. Essa tese estava fundamentada em estudos que, posteriormente, foram reformulados pelos próprios cientistas, em função da falta de estrutura hospitalar para tratamento de casos graves. Do ponto de vista social, essas incertezas provocam, também, estratégias de enfrentamento que não coincidem com as prescriçôes médicas oficiais, como ocorreu com um prefeito que autorizou o uso de um remédio homeopático (à base de cânfora) para 
ser administrado à população de seu município através dos agentes de saúde (medida que foi suspensa por determinação do Ministério Público), ou ainda das diversas receitas populares de suplementos vitamínicos (especialmente vitaminas $\mathrm{C}$ e D) para aumentar a imunidade.

O desmatamento progressivo e a antropização dos ambientes naturais comprometeram amplamente alguns nichos ecológicos, onde os coronavírus da vida selvagem geralmente estão confinados. Além disso, o consumo humano de animais silvestres e sua venda em locais insalubres, juntamente com a expansão contínua das terras agrícolas em áreas selvagens, o contato com o gado, animais domésticos e selvagens, o boom mundial da produção e tráfego de bovinos e as migraçōes forçadas (por questôes ambientais, econômicas ou políticas) vêm sendo responsáveis pelo transbordamento das barreiras entre as espécies e a emergência de doenças zoonóticas emergentes em várias regiōes do mundo (DECARO et al., 2010; CASCIO et al., 2011). Esses fatores de emergência fazem parte de várias publicaçôes científicas e subsidiam açóes, como por exemplo, a iniciativa One Health (composta por indivíduos da sociedade civil e organizaçóes científicas e profissionais, especialmente da área médica e veterinária), que incentiva estratégias mundiais para expandir as colaboraçóes e comunicaçóes interdisciplinares em todos os aspectos de atenção à saúde entre humanos, animais e meio ambiente (WOODALL, 2001). Um artigo recente apontou que a longa experiência adquirida com pesquisas de certos tipos de coronavírus em animais no campo da medicina veterinária poderia ser útil para abordar a origem e disseminação do SARS-CoV-2 e para fornecer modelos para entender fatores que precipitam pneumonia grave em pacientes com Covid-19, seguindo a abordagem da One Health (DECARO et al., 2020).

Por outro lado, o conceito de doenças infecciosas emergentes, seja aquele defendido através de uma abordagem pragmática pelo CDC (Centro de Controle e Prevenção de Doenças dos Estados Unidos), quanto pela abordagem históricoepistemológica realizada por Grmek $(1993,1995)$ também provocou um impacto sobre a forma de compreender o caráter interdependente das interaçóes humanosanimais-ambiente. Grmek (1993) apresentou quatro situaçôes nas quais as doenças poderiam ser classificadas: 1) ela existia antes de ser reconhecida pela ciência; 2) ela já existia mas aumentou em seu grau de letalidade em função de mudanças qualitativas e quantitativas em seu ambiente (o caso da Legionella, uma bactéria simples mas letal quando concentrada em precários sistemas de refrigeraçáo/ 
calefação); 3) ela foi introduzida em uma região onde não existia anteriormente (o caso das diversas doenças ditas tropicais); 4) ela emerge a partir da passagem de um reservatório não humano para humano (o caso das inúmeras doenças zoonóticas). Para Grmek (1993), a única possibilidade de uma doença ser considerada como nova advém da possiblidade de acidentes ocasionados por manipulação de organismos patogênicos em laboratório, bioterrorismo ou manipulações genéticas. Porém, mesmo nessa possibilidade, Grmek reconhece a existência de uma certa continuidade com o passado, pois nenhum organismo poderia originar-se de geração espontânea (GRISOTTI; AVILA-PIRES, 2010; GRISOTTI, 2016).

Como as açóes em saúde pública global dependem do conhecimento sobre a incidência e prevalência de doenças (ou em outras palavras, do que circula no ambiente), paralelamente às situaçóes apontadas por Grmek, incluímos uma outra situação que consideramos crucial para determinar a emergência de uma doença: o papel da subnotificação das doenças de notificação obrigatória e a falência no reconhecimento e registro de doenças incomuns (GRISOTTI; AVILA-PIRES, 2010; 2016). Esse aspecto tem sido um dos maiores limitadores do processo de vigilância e controle das doenças, pois o êxito dessas açoóes é obtido se os dados de registro forem corretos e coletados sistematicamente. Como eles dependem das esferas locais de gestão do sistema de vigilância em saúde, isso afeta consideravelmente as expectativas em torno das atividades em saúde global. Em um mundo de Estados-naçôes soberanos, a saúde continua a ser primariamente uma responsabilidade nacional, e apesar dos acordos e regulaçóes internacionais sobre a segurança global em saúde, os dados que alimentam o sistema são produzidos localmente e, nessa esfera, fatores extra-epidemiológicos influenciam o interesse em registrar e notificar doenças (GRISOTTI, 2016). No caso da Covid-19, todos os países estão realizando as notificações, porém cabe indagar se é a falta de testes ou uma estratégia interna de alguns países a causa da subnotificação do número real de casos confirmados e/ou de mortes.

Outro aspecto do debate situa-se no âmbito das políticas públicas de saúde. Assim como ressaltamos a perspectiva relacional e interdisciplinar na produção do conhecimento, o mesmo é válido para a necessária articulação e interdependência entre os vários setores vinculados à gestão em saúde e meio ambiente. O Estado brasileiro avançou na implantação da cobertura de assistência médica universal de saúde, viabilizada pelo SUS (desde a Constituição de 1988). Porém, se avançamos em assegurar assistência médica à população, o mesmo não pode ser dito em 
relação às medidas de saúde pública. A incipiente política de controle de vetores, as falhas no processo de registro e notificação de doenças infecciosas e parasitárias e a falta de articulação entre os setores de vigilância em saúde humana e animal são alguns exemplos para mostrar que não sabemos, de fato, o que realmente circula no ambiente. Sem esses dados, como fazer política pública, prospectar cenários e formular propostas de mitigação em casos de novas pandemias?

Recolocando, neste contexto, a centralidade das pesquisas científicas sobre doenças infecciosas emergentes (especialmente as de origem zoonótica) articuladas com os serviços de vigilância epidemiológica, é inevitável a defesa da formação do conhecimento interdisciplinar (por exemplo, entre a ciência médica e a veterinária) e da gestão interdependente dos setores e órgãos públicos ligados à saúde, para fomentar as políticas de saúde global na antecipação de novos eventos similares à pandemia de Covid-19. E tanto na produção do conhecimento quanto na gestão dos serviços de saúde pública, as ciências sociais possuem papel fundamental: quem poderá intermediar as relaçóes entre os pesquisadores da área da saúde humana e animal (ciência), a sociedade (com os diferentes interesses sociais e econômicos envolvidos), os técnicos da vigilância epidemiológica e os gestores do sistema de saúde, especialmente quando o processo de tomada de decisão envolver mudanças de hábitos e comportamentos? Epstein (1995) menciona a conclusão de uma conferência realizada por agências internacionais de saúde na qual o maior impedimento para o monitoramento e a detecção das doenças é a fragmentação da epidemiologia e sua não integração com outras disciplinas científicas; sugerindo a formação de uma metodologia integrativa e o reconhecimento da importância dos fatores econômicos e sociopolíticos no uso dos recursos naturais, na direção das mudanças globais e na determinação das exposiçôes, vulnerabilidades e acessos aos tratamentos. Janes et al. (2012), através de vários exemplos, reiteram também a importância das ciências sociais na criação de respostas apropriadas em saúde pública em relação aos riscos e emergência de epidemias.

O diagnóstico, as informaçôes sobre a exposição ao risco e o tratamento dependem, cada vez mais, de fatores socioantropológicos. Por isso, sociólogos e antropólogos, através de suas peculiares ferramentas teóricas e metodológicas, detêm, muitas vezes, a chave para a explicação de padróes epidemiológicos particulares e para o auxílio na construção de uma consciência de interdependência, requerida para a governança global em saúde. 


\section{Referências}

BOURDIEU, P. Introdução a uma sociologia reflexiva. $O$ poder simbólico. Rio de Janeiro: Bertrand Brasil, 1998. p. 17-58.

CASCIO, A. et al. The socio-ecology of zoonotic infections. Clin Microbil Infect, v. 17, p. 336$342,2011$.

DECARO, N. et al. Covid-19 from veterinary medicine and one health perspectives: What animal coronaviruses have taught us. Res Vet Sci. Aug., v. 131, p. 21-23, 2020.

ELIAS, N. Introdução à Sociologia. Lisboa: Edições 70, 1999.

EPSTEIN, P. R. Emerging Diseases and Ecosystem Instability: New Threats to Public Health. Am J Public Health, v. 85, n. 2p. 168-172, 1995.

GRMEK, M. D. Declin et émergence des maladies. Hist. Cienc. Saude-Manguinhos, v. 2, p. 9-32, 1995.

. Le concept de maladie émergente. Hist. Phil. Life Sci., v. 15, p. 282-296, 1993.

GRISOTTI, M. Governança em saúde global no contexto das doenças infecciosas emergentes. Dossiê: Estado e sociedade em tempos de transnacionalismo. Civitas, v. 16, n. 3, p. 377-398, 2016.

GRISOTTI, M.; AVILA-PIRES, F. D. The concept of emerging infectious disease revisited. In: MUKHERJEA, A. (Ed.). Understanding emerging epidemics: social and political approaches. Advances in medical sociology. v. 11. Londres: Emerald, 2010.

JANES, C. R et al. Emerging infectious diseases: the role of social sciences. The Lancet, v. 380, n. $1,2012$.

OCHMAN, H.; LAWRENCE, J. G.; GROISMAN, E. A. Lateral gene transfer and the nature of bacterial innovation. Nature, v. 405, p. 299-304, 2000.

WOODALL, J. Global surveillance of emerging infectious disease: the ProMED-mail perspective. Cadernos de Saude Publica, v. 17, supl., p. 147-154, 2001. 